\title{
Could Private Legislation Be the First Key to Unlocking the Nation's Information Resources in the Battle Against Misinformation?
}

Michelle M. Wu

Georgetown University Law Center, mmw84@law.georgetown.edu

This paper can be downloaded free of charge from:

https://scholarship.law.georgetown.edu/facpub/2411

https://ssrn.com/abstract=3892281

Legal Reference Services Quarterly, forthcoming.

This open-access article is brought to you by the Georgetown Law Library. Posted with permission of the author. Follow this and additional works at: https://scholarship.law.georgetown.edu/facpub

Part of the Intellectual Property Law Commons 
The final, published version in Legal Reference Services Quarterly can be found at:

https://www.tandfonline.com/doi/full/10.1080/0270319X.2021.1966239

\title{
Could Private Legislation Be the First Key to Unlocking the Nation's Information Resources in the Battle Against Misinformation?
}

\author{
Michelle M. $\mathrm{Wu}^{1}$
}

\section{Table of Contents}

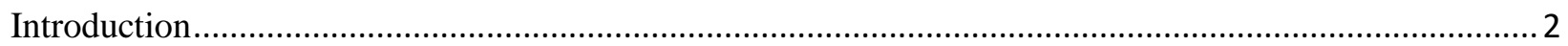

Google Agreements with Library Partners ............................................................................... 4

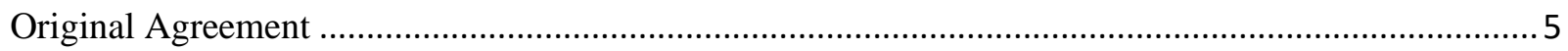

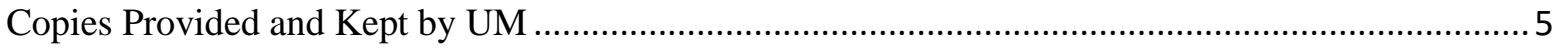

Original Agreement - Ownership of Digital Copies ............................................................... 6

Original Agreement - Use of UM's Digital Copies ..................................................................... 7

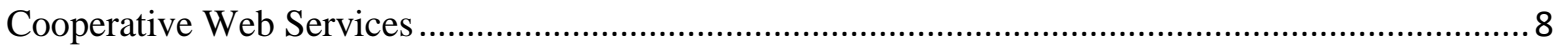

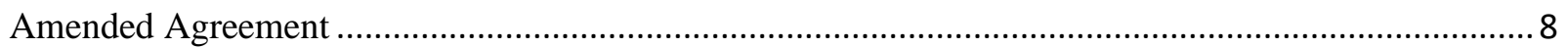

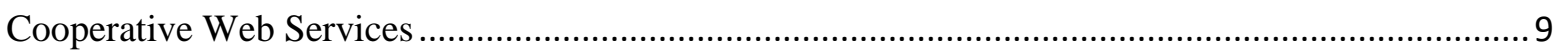

Why the Public Interest Justifies Asking Congress to Intervene ...................................................... 11

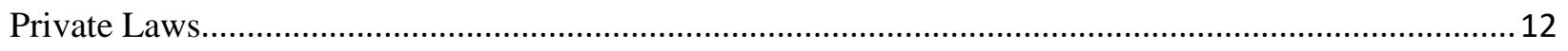

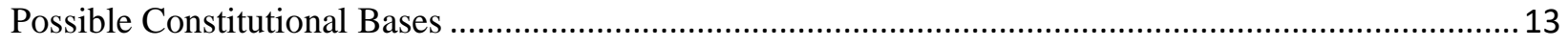

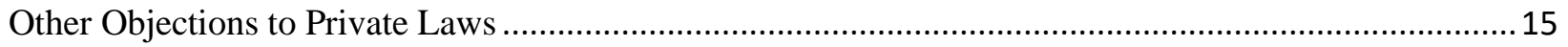

Post-Enactment Actions By Library Partners …............................................................................. 15

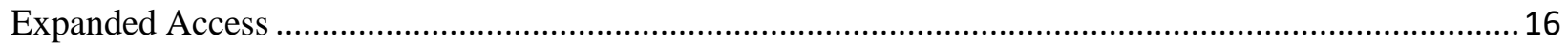

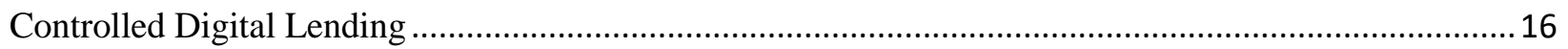

Fair Use Analysis for the Sharing of Library Images ................................................................... 19

Receiving Library's Written Assumption of Responsibility...............................................................20

Notice of Copyright and Limitation of Liability .......................................................................... 21

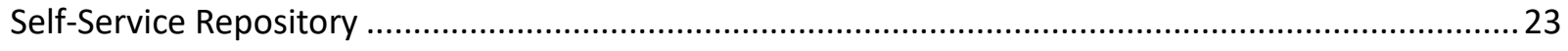

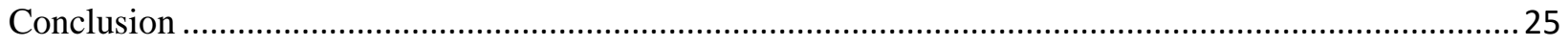

\footnotetext{
${ }^{1}$ Retired law library director and professor of law. Formerly the law library director at Georgetown University Law Center, Hofstra Law School, and the University of Houston Law School, and a professor of law at Georgetown University Law Center and Hofstra Law School.
} 


\section{Introduction}

The creation of a user-friendly, accessible graphical web fundamentally changed information seeking behaviors, in many ways for the better. ${ }^{2}$ More people had faster access to information, in a more convenient manner, and in forms that could be consumed anywhere (so long as the user has a device and a data connection). Research was no longer confined entirely to specific physical repositories of information. While the digital divide meant that some have not yet seen the full benefits of this movement, it is undeniable that more people each year have greater access to information. ${ }^{3}$

However, there are downsides to such unfettered and convenient access as well. It has been well documented that ease of access triumphs over quality information in user choice, with users settling for a "good enough" convenient, unverified, online source over consulting a less convenient source that they know is more likely to be reputable. ${ }^{4}$ Various other studies have shown that people have difficulty evaluating the validity of content online, ${ }^{5}$ and even when aware of their own inability to judge, will still rely on information that they can retrieve easily, even when accuracy is questionable. ${ }^{6}$ As applies to online information, this means that a fair number of people are willing to rely on sources like social media ${ }^{7}$ or falsified information ${ }^{8}$ that are readily available online without any attempt to check the information if there is no equally easy way to perform such a check.

\footnotetext{
${ }^{2}$ See, Xi Niu et al., National Study of Information Seeking Behavior of Academic Researchers in the United States, 61 J. AMER. SOC'Y INFO. SCI. \& TECH. 869 (2010); Feifei Liu, How Information-Seeking Behavior Has Changed in 22 Years, https://www.nngroup.com/articles/information-seeking-behavior-changes/.

${ }^{3}$ See, Emily A. Vogels, Digital Divide Persists Even as Americans with Lower Incomes Make Gains in Tech Adoption, PEW RES. CTR. (June 22, 2021), https://www.pewresearch.org/fact-tank/2021/06/22/digital-divide-persistseven-as-americans-with-lower-incomes-make-gains-in-tech-adoption/.

${ }^{4}$ See, Michael Barthel et al., Measuring News Consumption in a Digital Era, Pew RES. CTR. (Dec. 8, 2020), https://www.journalism.org/2020/12/08/measuring-news-consumption-in-a-digital-era/ (noting that most Americans do not pay for news and social media is generally used as regularly for news as official newspapers/sites); Lynn Silipigni Connaway, Timothy J. Dickey \& Marie L. Radford, "If It Is Too Inconvenient, I'm Not Going After It:" Convenience as a Critical Factor in Information-seeking Behaviors, 33 LIB. \& INFO. SCI. RES. 179 (2011).

${ }^{5}$ Sam Wineburg et al., Evaluating Information: The Cornerstone of Civic Online Reasoning, STANFORD DigITAL REPOSITORY (2016). Available at: http://purl.stanford.edu/fv751yt5934

${ }^{6}$ Supra note 4.

${ }^{7}$ See, Elisa Shearer \& Elizabeth Grieco, Americans Are Wary of the Role Social Media Sites Play in Delivering the News, PEw RES. CTR. (Oct. 2, 2019), https://www.journalism.org/wpcontent/uploads/sites/8/2019/09/PJ_2019.09.25_Social-Media-and-News_FINAL.pdf.

${ }^{8}$ See, Max Read, How Much of the Internet Is Fake? Turns Out, a Lot of It, Actually, N.Y. MAG. (Dec. 26, 2018), https://nymag.com/intelligencer/2018/12/how-much-of-the-internet-is-fake.html (detailing the proliferation of fake users, businesses, news, commentary, traffic on the web); Amy Mitchell et al., Americans Who Mainly Get Their News on Social Media Are Less Engaged, Less Knowledgeable, Pew RES. CTR. (July 30, 2020), https://www.journalism.org/2020/07/30/americans-who-mainly-get-their-news-on-social-media-are-less-engagedless-knowledgeable/.
} 
While some of this behavior could be due to a genuine disinterest in the truth or predisposition for only information that matches a person's own worldview, ${ }^{9}$ part of it can also be explained by the fact that unverified information overwhelms the amount of reliable data that is found on the open web. Because of the unfiltered nature of the web, opinions, random comments, falsified facts, and fake news can be posted faster and in greater number than reviewed, fact-checked, edited documents, the latter categories taking time, money, and human manpower to create. ${ }^{10}$ Bots play an enormous role in this type of rapid-fire misinformation proliferation, ${ }^{11}$ but a less discussed contributor is the relative scarcity of reliable information. After all, bots could be set to spread accurate information as well as inaccurate information, if accurate information is available to be spread (and if society thinks that bots can be used in this way ethically).

The scarcity of verifiable information is attributable in part to the fact that many reliable documents are still only found in print or microform in libraries across the nation or available only on pay-walled databases. Until there is a mechanism through which these reputable materials are made easily findable and accessible by the general public, even those who are minimally interested in checking facts will be discouraged from doing so. The effort in hunting down information is significant, and it becomes easier to simply accept that what one has read online is roughly accurate. ${ }^{12}$

This article suggests that private legislation could make library collections available in a manner likely to decrease the difficulty in accessing reliable information. Specifically, it suggests (1) private legislation to overcome the contractual barriers established by Google to prevent their Partner Libraries from making full use of the digital images they received as part of the Google Books project, and (2) libraries making these materials available to the nation through means that expand meaningful access substantially while respecting copyright.

This construct would not overcome the digital divide nor move those that are disinterested in the truth, but it could make a significant difference for those willing to put in a minimum amount of effort to verify a data point before publicizing or challenging it. The Internet Archive has already demonstrated the power of digitization in fact verification through

\footnotetext{
${ }^{9}$ Anna Lucia Schmidt et al., Anatomy of News Consumption on Facebook, 114 PNAS 3035 (2017), https://www.pnas.org/content/pnas/114/12/3035.full.pdf.

${ }^{10}$ See, Srijan Kumar \& Neil Shah, False Information on Web and Social Media: A Survey (2018), https://www.cc.gatech.edu/ srijan/pubs/paper-survey.pdf.

${ }^{11}$ See, Edmund L. Andrews, How Fake News Spreads Like a Real Virus, STAN. EngineERING MAG. (Oct. 9 2019), https://engineering.stanford.edu/magazine/article/how-fake-news-spreads-real-virus; Christina Nemr \& William Gangware, Weapons of Mass Distraction: Foreign State-Sponsored Disinformation in the Digital Age (March 2019), https://www.state.gov/wp-content/uploads/2019/05/Weapons-of-Mass-Distraction-Foreign-State-SponsoredDisinformation-in-the-Digital-Age.pdf.

${ }^{12}$ See, Elisa Shearer \& Amy Mitchell, News Use Across Social Media Platforms in 2020, Pew Res. CTR. (Jan. 2021), https://www.journalism.org/wp-content/uploads/sites/8/2021/01/PJ_2021.01.12_News-and-Social-

Media_FINAL.pdf (noting the heavy reliance on news sources even when readers know that they might be inaccurate).
} 
their partnership with Wikipedia to turn all the links in the latter's articles blue, clickable and leading to an officially published source. ${ }^{13}$

It is important to note at the outset that at least two developments could make the necessity of the initial step - private legislation - moot. The first is the digitization effort by the Internet Archive, which has been digitizing and lending public domain and copyrighted materials, the latter under controlled digital lending (CDL), for over a decade. Its collection comprises over $22 \mathrm{M}$ works, and since the pandemic, it has been developing a wider reach through resource-heavy partners like the New Zealand National Library ${ }^{14}$ which should increase its digital offerings considerably in the coming years. If its collection eventually includes the titles targeted by this article, then the first part of the proposal would be unnecessary to reach its purpose.

The second potential development involves HathiTrust, where the large academic libraries that partnered with Google on the initial Google Books project have aggregated their digital objects. The database now contains many more items than just those digitized by Google, but the Google-corpus still makes up a substantial part of the collection. HathiTrust generally has provided limited access to copyrighted works, primarily only to members, and the full-text only to the contributing members or to community members with certified print disabilities. ${ }^{15}$ With the pandemic, though, they opened access to full-text much more broadly under a service they called an Emergency Temporary Access Service (ETAS), ${ }^{16}$ through which any member library could access full-texts of works that their libraries owned in print. This service is intended to be temporary, and applies only to "member libraries that have experienced unexpected or involuntary, temporary disruption to normal operations, requiring it to be closed to the public, or otherwise restrict collection access services." 17 If ETAS ends with the pandemic, as it currently appears slated to do, then it has no effect on this paper. If, however, HathiTrust decides to continue to provide full-text access and to allow more than members to gain access, the purpose of this paper may have been accomplished even without the proposed legislation.

\section{Google Agreements with Library Partners}

\footnotetext{
${ }^{13}$ Klint Finley, The Internet Archive Is Making Wikipedia More Reliable, WIRED (Nov. 3, 2019), https://www.wired.com/story/internet-archive-wikipedia-more-reliable/.

${ }^{14}$ National Library Signs Historic Agreement With Internet Archive, SCOOP INDEPENDENT NEWS (July 13, 2021), https://www.scoop.co.nz/stories/CU2107/S00072/national-library-signs-historic-agreement-with-internetarchive.htm.

15 “Access to materials in the repository is determined by 1) copyright law and 2) permissions granted by individual rights holders. Works that HathiTrust partners do not have rights to make available are not made available, or are made available under very limited circumstances (such as to certified users with disabilities who need to make use of a screen reader in order to access materials). The primary function of HathiTrust is long-term preservation, with access to materials secondary, and we make every effort to respect the rights of copyright holders and comply with copyright law.” https://www.hathitrust.org/help_general.

${ }^{16}$ HathiTrust Response to Covid-19, https://www.hathitrust.org/covid-19-response (last visited July 12, 2021).

${ }^{17}$ https://www.hathitrust.org/ETAS-Description (last visited July 12, 2021).
} 
In 2004, Google announced that it had partnered with Harvard, Stanford, the University of Michigan, Oxford University, and the New York Public Library to digitize part or all of their collections for inclusion in what was then called Google Print. ${ }^{18}$ As the project continued, additional libraries were added as partners. ${ }^{19}$ The announced intention was to create a large, publicly searchable library, and the result is what the world knows today as Google Books - a database that allows users to search books, see snippets of the pages relevant to the search, and (in some cases) buy or license the books shown.

The digitization agreements with the participating libraries to produce this database at the outset contained terms not just related to the digitization of the libraries' books but also rules for the use of the subsequent digital images. Google promised to deliver to participating libraries ecopies of the works digitized from their respective collections but simultaneously limited what the libraries were permitted to do with them. Examples of the language can be found in the agreements with the University of Michigan (UM), which it has made publicly available. ${ }^{20}$ Since not every agreement is public, the assumption in this paper is that most agreements are similar to one of the two agreements between Google and UM. And while UM's second agreement modified the first, it is impossible to know if every library that entered into an initial agreement executed a similar amendment, so the terms of each agreement will be analyzed to pinpoint the problematic clauses.

\section{Original Agreement}

\section{Copies Provided and Kept by UM}

\subsection{U of M Digital Copy. Google agrees to provide to $\mathrm{U}$ of $\mathrm{M}$ a copy of all Digitized Selected Content that has been "successfully processed" within thirty (30) days after the Selected Content is Digitized, or in a timeframe mutually agreed up by the Parties...}

2.5.2 Within 3 years of the time that Google has transferred Digitized Selected Content to $\mathrm{U}$ of $\mathrm{M}$, if Google decides not to use that content due to a dispute with a third-party, $\mathrm{U}$ of $\mathrm{M}$ will destroy that content (so long as it is in print and protected by copyright) from the U of M Digital Copy...

\footnotetext{
${ }^{18}$ David A. Vise, Google to Digitize Some Library Collections: Harvard, Stanford, New York Public Library Among Project Participants, WASH. POST (December 14, 2005). The number of library partners increased over the course of the project and the full listing can be found here: https://books.google.com/intl/en_au/googlebooks/partners.html.

${ }^{19} \mathrm{https}$ ///books.google.com/intl/en_au/googlebooks/partners.html (last visited July 7, 2021).

${ }^{20}$ The original agreement is at https://staff.lib.umich.edu/sites/staff.lib.umich.edu/files/2020-06/um-googlecooperative-agreement.pdf and the amended version at https://staff.lib.umich.edu/sites/staff.lib.umich.edu/files/2020-06/Amendment-to-Cooperative-Agreement.pdf.
} 
These two provisions set forth Google's obligations to provide copies of digital content to UM as well as UM's obligation to delete such images under certain conditions. The first provision (2.5) is not problematic, but the second one (2.5.2) is. While Google's desire to limit liability by destroying any copies of works that might be disputed is understandable, this clause arguably removes a resource from UM's hands that it has a strong argument to retain. If there is a liability claim, it is most likely to rest on an allegation of copyright infringement, and since neither party owns the copyrights, each party should be independently responsible for any use of the images that infringe on a copyright owner's rights. UM's liability if it keeps and uses such a work would rest only on it, and Google's involvement in UM's use should be viewed only through the lens of a service provider. While the term may be reasonable for disputes outside of copyright (e.g., allegations of theft), Google should have retained no other rights to dictate UM's destruction of the copies.

In illustration, consider if UM had instead contracted with a third party to digitize a work. Even if the original document had turned out to be a pirated copy, the third party would not in the normal course of events be liable for copyright infringement. ${ }^{21}$ Instead, the requesting party (and ultimate owner/user of the infringing copy) would have been the party responsible for answering any claims on infringement. In such an instance, depriving UM of the copy as well as the opportunity to defend its use, if it had a colorable argument for legitimate use (e.g., orphan work for which a reasonable search had been conducted and failed), seems counter to innovation or the ability to establish a fair use.

In this particular agreement, Google could have appropriately limited its liability in case of a conflict simply by deleting its own copy, allowing UM to do with its copy what it wished while also assuming $100 \%$ of the responsibility for any claims of infringement arising from its use.

Practically speaking, except where any of the contracting libraries has a continuing relationship with Google to digitize their collections beyond 2018, this clause is likely moot, as the three-year period after conveyance of the digital copies would have expired.

\section{Original Agreement - Ownership of Digital Copies}

\subsection{Ownership and Use of U of M Digital Copy. Neither U of M or Google shall have any ownership or license rights to the Available Content that is Digitized (i.e., to the materials underlying the digitization process), except where UM already has such rights. As between Google and $\mathrm{U}$ of $\mathrm{M}$ and subject to the provisions of this}

\footnotetext{
${ }^{21}$ While it is possible that a third party might be contributorily negligent if it knows that its actions are infringing, if this knowledge is lacking, its ignorance and the lack of involvement in subsequent use of the work should free it from any consequences. Digitization by itself has typically not been found to be infringing (e.g., not been controversial in the cases before courts; see Authors Guild, Inc. v. HathiTrust, 755 F.3d 87 (2d Cir. 2014) and Authors Guild v. Google, Inc., 804 F.3d 202 (2d Cir. 2015) as examples. It is typically only use after reproduction that triggers legal action and court scrutiny.
} 
section 4, $\mathrm{U}$ of $\mathrm{M}$ shall own all rights, title, and interest to the $\mathrm{U}$ of M Digital Copy.

This provision is relevant only insofar as it clearly states that UM owns all rights, title and interest to the UM digital copy, while other provisions in the same agreement explicitly contradict the ownership principle. Ownership comes through the alienation of rights, ${ }^{22}$ where the previous owner surrenders the object and any rights of control to a new owner. Ownership typically comes with the undivided right to do what the new owner wishes with the owned item without any interference from previous owners. 2.5.2, discussed above, is one such example of how that right is compromised, giving Google the rights to dictate what happens to the digital copy in specific situations. The effect of other clauses will be discussed in later sections.

\section{Original Agreement - Use of UM's Digital Copies}

\subsubsection{Use of U of M Digital Copy on U of M Website. U of M} shall have the right to use the U of M Digital Copy, in whole or in part at U of M's sole discretion, as part of services offered on $U$ of M's website. U of M shall implement technological measures (e.g., through use of the robots.txt protocol) to restrict automated access to any portion of the $\mathrm{U}$ of $\mathrm{M}$ Digital Copy or the portions of the $\mathrm{U}$ of $\mathrm{M}$ website on which any portion of the $\mathrm{U}$ of $\mathrm{M}$ Digital Copy is available. $\mathrm{U}$ of $\mathrm{M}$ shall also make reasonable efforts (including but not limited to restrictions placed in Terms of Use for the $U$ of $M$ website) to prevent third parties from (a) downloading or otherwise obtaining any portion of the $U$ of $M$ Digital Copy for commercial purposes, (b) redistributing any portions of the U of M Digital Copy, or (c) automated and systematic downloading from its website image files from the $U$ of $M$ Digital Copy. $\mathbf{U}$ of $\mathbf{M}$ shall restrict access to the $\mathbf{U}$ of $\mathbf{M}$ Digital Copy to those persons having a need to access such materials and shall also cooperate in good faith with Google to mutually develop methods and systems for ensuring that the substantial portions of the $U$ of $M$ Digital Copy are not downloaded from the services offered on $U$ of $M$ 's website or otherwise disseminated to the public at large. (emphasis added)

\footnotetext{
22 "Under the common law, restraints on the alienation of property were disfavored, and the owner of property could generally dispose of property as the owner desired. Accordingly, under the modern practice, restraints on alienation of property are disfavored as contrary to public policy. The rule against unreasonable restraints on alienation is founded entirely upon considerations of public policy, specifically, the idea that the free alienability of property fosters economic and commercial development." 61 AM. JUR. 2D Perpetuities, Etc. $\S 88$
} 
The highlighted text in this provision regarding online access also runs counter to the statement that UM owns their digital copies. Each of the restrictions in 4.4.1 --- prohibiting automated access, limiting use by third parties, and limiting access by the public --- ensure that Google remains a rights holder to the UM images, regardless of where they are stored and despite contract terms setting UM as the "owner" of these objects.

The provisions limiting third-party use and public access are particularly troubling, as they make no exception for images of public domain works, fair uses, and make it impossible for the library to use the digital copy of the work in the same manner as it would have used the original. Tying a library's hands to use its own resources for education, research, scholarship, and teaching serves only the purpose of protecting Google's monopolization on the use of those works.

\section{Cooperative Web Services}

\subsubsection{Use of U of M Digital Copy in Cooperative Web Services.} Subject to the restrictions set forth in this section, $\mathrm{U}$ of $\mathrm{M}$ shall have the right to use the $\mathrm{U}$ of $\mathrm{M}$ Digital Copy, in whole or in part at $U$ of M's sole discretion, as part of services offered in cooperation with partner research libraries such as the institutions in the Digital Library Federation. Before making any such distribution, $\mathrm{U}$ of $\mathrm{M}$ shall enter into a written agreement with the partner research library and shall provide a copy of such agreement to Google, which agreement shall: (a) contain limitations on the partner research library's use of the materials that correspond to and are at least as restrictive as the limitations placed on $U$ of M's use of the $U$ of $M$ Digital Copy in section 4.4.1; and (b) shall expressly name Google as a third party beneficiary of that agreement, including the ability for Google to enforce the restrictions against the partner research library. (emphasis added)

Again running counter to ownership rights, UM's ability to share any digital copy even with existing partners is subject to Google's terms, and in some cases, to Google's consent. Credit to Google for not prohibiting this type of sharing outright, but the written limitations - (1) requiring any partners to agree in writing to comply with the original terms of use between Google and UM and (2) essentially giving Google the right to sue if that agreement is breached - are substantial barriers to fair use. 
The amended agreement between UM and Google has many improvements, but the issues identified above still exist. The relevant provisions are below with brief commentary. The descriptive terms of "Non-Settlement" and "Settlement" in the clause below can be ignored, as the Settlement Agreement referenced was never finalized, meaning that there is no distinguishing between the two; every copy is a non-settlement copy. The Amended Agreement itself became void when the Settlement Agreement was rejected, but the terms of the Amended Agreement (Clause 34) indicated that should this come to pass, Google and UM would execute a separate agreement to adopt certain terms, including that reproduced below. For that reason, the clause still deserves some discussion.

Cooperative Web Services

16. Cooperative Web Services. Section 4.4.2, "Use of U of M Digital Copy in Cooperative Web Services," shall be replaced with the following:

"4.4.2 Use of U of M Digital Copy in Cooperative Web Services. Except as set forth in Section 4.4.3 and the terms of U of M's Library-Registry (Fully Participating) Agreement and this Section, and provided $\mathrm{U}$ of $\mathrm{M}$ has obtained all necessary permissions, rights, and licenses from third parties, $\mathbf{U}$ of $\mathbf{M}$ shall have the right to use the $U$ of $M$ Digital Copy, in whole or in part at $U$ of M's sole discretion, as part of web services offered in cooperation with partner academic libraries and/or partner public research libraries (such as the New York Public Library), including, without limitation, the institutions in the Association of Research Libraries, Digital Library Federation and similar organizations. Such services may include, without limitation, indexes and finding tools, as well as the reproduction and display of the $\mathrm{U}$ of $\mathrm{M}$ Digital Copy, to the extent not otherwise prohibited by this Agreement and U of M's Library-Registry (Fully Participating) Agreement. Before $\mathbf{U}$ of $\mathbf{M}$ makes any such use that involves the distribution of one or more Digital Copies included within the $U$ of $M$ Digital Copy to any such library, such library must enter into a written agreement with Google, the form of which Google will provide 
to $\mathbf{U}$ of $\mathbf{M}$. Such agreement will (a) prohibit such receiving library from redistributing such Digital Copies from the $\mathrm{U}$ of $\mathrm{M}$ Digital Copy to any third party, except that $\mathrm{U}$ of $\mathrm{M}$ may authorize such library to redistribute such Digital Copies as an agent and on behalf of $U$ of $M$ subject to the rights and restrictions set forth in this Agreement, provided $\mathrm{U}$ of $\mathrm{M}$ would have the right under this Agreement to make such redistribution directly, (b) limit the receiving library's use of such Digital Copies from the $U$ of $M$ Digital Copy to the sole purpose of providing cooperative web services as set forth herein, which limitations on use shall in all events be at least as restrictive as those placed on U of M's use of the U of M Digital Copy in this Agreement and, if applicable, the Library-Registry (Fully Participating) Agreement, and (c) require such receiving library (i) to use reasonable efforts to prevent third parties from bulk downloading substantial portions of such Digital Copies, and (ii) to implement technological measures (e.g., through use of the robots.txt protocol) to restrict automated access to any part of such entity's website where substantial portions of such Digital Copies are available. $\mathrm{U}$ of $\mathrm{M}$ will have the right to approve those sections of the form of such agreement that grant any rights that materially differ from the rights granted to $\mathrm{U}$ of $\mathrm{M}$ with respect to the use of such portions of the $U$ of M Digital Copy in the Agreement." (emphasis added)

The revised language is a marked improvement over the original. Under it, UM has much greater freedom in determining how it wants to use its digital copies in cooperation with its partners. However, later sentences and clauses belie that seeming liberation.

The language " $U$ of $M$ shall have the right to use the $U$ of $M$ Digital Copy, in whole or in part at U of M's sole discretion" makes it appear that UM really does have ownership, and that Google has given up any stake in the copies. Jump a few sentences down, though, and the restrictions on use reappear. The clause requires any library receiving a digital copy from UM to enter into an agreement with Google, and the required terms of that agreement include a prohibition on redistribution. As this new agreement is between the receiving library and Google, the latter continues to hold the legal rights to enforce compliance.

Notably, there is still no cut-out in this clause for works that have fallen into the public domain so the restrictions apply whether or not the copies are of works still protected by copyright or works in the public domain. 


\section{Why the Public Interest Justifies Asking Congress to Intervene}

The resulting Google Books database has been addressed by courts but only through the lens of copyright (Authors Guild v. Google). What has not been discussed is how some of the benefits that Google gained were far beyond what was necessary to the project, impinged on the public good, and were (arguably) subsidized, at least in part, by public funds. In other words, might this be a novel case of unjust enrichment ${ }^{23}$ ? This article considers whether or not it would be in the interests of the nation to advocate for private legislation that nullifies the clauses that interfere with the public good, allowing public investments to be maximized not just for Google's private enterprise but also for a public purpose.

The success of the Google Books project rested on making a copy of a corpus of content that Google did not own and had no access to. But for the libraries that participated in the project, Google would have not been able to obtain the content to be digitized, at least not without financial and time investments far beyond what was used in digitization itself. Libraries provided access to works spanning centuries, including rare titles unavailable even through secondhand markets, and since these works had been selected by libraries, part of the contribution came in the form of the collection development expertise to select the most historically valuable works and exclude poorly constructed ones.

Some of these libraries, like the University of Michigan's, are public, and even where the majority of funding might now come from private sources (e.g., tuition), historically, their collections were built in large measure through public funds. Their staff time and expertise at the time of source selection falls under the same analysis, made possible only through public investment. In some cases, more recent staff time and even on-site space was provided to Google to facilitate processing, both of which would also be considered public resources.

Even private libraries receive public funds for their collections, whether indirectly through tuition (and federal financial aid) or directly through grants.

There is significant public interest in allowing both public and private libraries to determine how best to use the materials owned, as they are the ones with the societal obligations to provide the public with reliable and long-term access to the content acquired. They would be best placed to understand their communities' needs and the mechanisms available to meet those needs.

By using these libraries' collections to build a database through which it can build income generating activities (e.g., print on demand ${ }^{24}$ ), Google has leveraged public resources for its private benefit. Further, this private benefit is an extended advantage, not encompassing only access to and copies of the works that it digitized, but an artificial extension where it can control

\footnotetext{
23 The reason this is an unusual claim is because unjust enrichment typically will not be recognized where a contract exists. However, the argument in this case is that the parties to the contract were not the only interested parties, and the unjust enrichment occurred at the cost of the public, which was not a party to the Google agreements.

${ }^{24}$ For a description of its print on demand service, see Ryan Singel, Google Lets You Custom-Print Millions of Public Domain Books, WIRED (Sept. 17, 2009), https:/www.wired.com/2009/09/google-books-publish-on-demand/.
} 
the distribution of content that it would not have had access to without the contributing libraries. The owners of the original copies (libraries) are limited in what they can do with the digital copies whereas they would not have been so constrained had they outsourced the digitization to another third party.

Of course, the argument on the flip side is that Google provided free labor, and that contracting parties are always welcome to bargain for terms that they think are fair. While that is true, that what the University of Michigan (and other libraries agreed to) may have been what they considered fair to their institutions, the question here is whether or not the contracts were fair to the public, which subsidized the costs of the content and labor.

Google could also argue that it has provided the public with access to the materials scanned, so enabling partner libraries to do the same is unnecessary. It has indeed provided a public service, in the form of its searchable database, snippets, and associated tools (e.g., ngram), but that public service was achieved while simultaneously suppressing partner libraries' ability to build on the content to build better engines, more equitable access, or public services. Google's services could have been accomplished without limiting the non-profit sector's ability to make full use of the images obtained.

As Google now arguably has reaped much of the benefits of the bargain, obtaining content of books without ever paying for them, being the first entity to create a searchable database of books, and having experimented with business models based on the content, it is now time to consider whether the agreements damage the public good beyond the private interests of letting the contract terms stand. To allow each party to retain some benefit of the bargain, most of the terms could remain undisturbed, with only those clauses contradicting the principles of alienation neutralized. The mechanism through which such an agreement might be amended without the parties' consent is through private legislation.

\section{Private Laws}

Private laws are simply pieces of legislation that are intended to apply only to the parties named in that legislation. ${ }^{25}$ This is contrasted with public laws that have general applicability. Private laws are not frequently enacted, and over the last decade there have been fewer than a handful each year, but when this vehicle has been used, the subject matter is fairly varied.

Private legislation can be as simple and uncontroversial as authorizing a national award (e.g., bestowing Medal of Honor ${ }^{26}$ ), or can be the end result of months'- or years'- long efforts. Examples in this latter category include granting specific relief to individuals or groups (e.g., authorizing special immigration treatment ${ }^{27}$ ), disbursing of funds to a group facing unusual

\footnotetext{
${ }^{25}$ Matthew Mantel, Private Bills and Private Laws, 99 LAw LiBR. J. 87, 88 (2007).

${ }^{26}$ Pvt. L. 115-1. To authorize the President to award the Medal of Honor to John L. Canley for acts of valor during the Vietnam War while a member of the Marine Corps.

${ }^{27}$ Pvt. L. No. 107-6 (2002).
} 
injuries, ${ }^{28}$ empowering a court to resolve specific disputes (e.g., delegating to the Court of Claims), ${ }^{29}$ or remedying a particular government harm to an identified party. ${ }^{30}$ Its use has been likened to an equitable action at law, where action is taken when a legal authority's conscience is pricked, as opposed to correcting an actual violation of an enacted law or regulation. ${ }^{31}$

There is no strict definition of federal private laws, though one 1966 article remarked on its seemingly self-imposed limits:

...private legislation presently deals only with relationships

between individuals and the Government. Specifically, only two

categories of private bills are passed: (1) those dealing with claims

against the United States, including waiver of claims by the

Government against individuals; and (2) those excepting

individuals from certain immigration and naturalization

requirements. Bills dealing with relations between private persons,

formerly enacted on occasion, are no longer passed. ${ }^{32}$

... and pointed out that there had to be some commonsense limits to what actions were permitted through this vehicle. The article concluded that a private law must still fall within the enumerated powers of Congress; otherwise, individuals and groups could circumvent state, court, and executive authority through private legislation. ${ }^{33}$

Given that contracts fall squarely within the province of the states, even if Congress determined that the Google-Library Partner contracts caused public harm, would they have the power to act?

\section{Possible Constitutional Bases}

Despite the division between federal and state authority, the Google Books project contains some unique features that could justify federal intervention in what would normally be a state matter. All of those features implicate Congress' powers to regulate interstate commerce.

\footnotetext{
${ }^{28}$ Pvt. L. No. 104-1 (1996) (to pay Benchmark Rail Group for work done after the Northridge earthquake, after it had been initially been denied payment due to California law).

${ }^{29}$ Pvt. L. 95-60 (1978).

${ }^{30}$ Priv. L. 106-6 (2000) (directing payment Akal Security, Inc. for services performed but not paid in connection with an Army contract); Priv. L. 104-1 (1996) (directing FEMA to pay Benchmark Rail Group, Inc. for work performed under the Stafford Act); Priv. L. 101-11 (1990) (directing payment to Nebraska Aluminum Castings, Inc. for costs arising out of Army rejection of a solicitation proposal); Priv. L. 100-9 (1987) (directing payment to Purvis Construction Co. based on a contract claim for the construction of World's Fair exhibit buildings in 1962).

${ }^{31}$ Private Bills in Congress, 79 HARV. L. REV. 1684, 1686 (1966).

${ }^{32} \mathrm{Id}$.

${ }^{33} I d$. at 1685 .
} 
First, the contract terms dictate what Library Partners can and cannot do with the digital copies online. The terms interfere with commerce both directly and indirectly, directly through the clauses that prohibit sharing with anyone engaging in the same business as Google and indirectly through the clauses that limit sharing with all others.

Second, antitrust issues are raised through the same limiting clauses. Given the specific wording of the clauses, in particular, the prohibition against sharing digital copies with entities "providing search or hosting services substantially similar to those provided by Google," the monopolistic intent is clear. The clause has no purpose other than to preserve Google's monopoly. Of course, monopolies by themselves are not necessarily illegal; after all, copyright's very nature is monopolistic.

But, Google's monopoly was gained using public resources, which should give rise to a greater state and federal right to scrutinize the monopoly and the resources being used to further the monopoly. There is no purpose to restricting a library's use of content that it has acquired except to prevent it from "competing" with Google. Since the library would have to comply with copyright in any case, its subsequent use of those digital objects would still be subject to copyright, so any interest served by copyright survives regardless of contract terms and should be irrelevant to its agreement with Google.

Another antitrust-like argument is one that claims federal jurisdiction under a permutation of the essential facilities doctrine. This doctrine historically has four requirements:

(1) control of the essential facility (resource) by a monopolist;

(2) a competitor's inability practically or reasonably to duplicate the facility;

(3) the denial of the use of the facility to a competitor; and

(4) the feasibility of providing competitive access to the facility. ${ }^{34}$

....and when these elements are met, the government may intercede to break an otherwise legitimate monopoly. The doctrine has most often been used where an entity has a legal monopoly in one aspect of business and uses its control to extend the monopoly into an adjacent market. ${ }^{35}$

The argument in this case is that the digital images are an essential facility, in the form of an information conduit, and that (a) the contracts that Google has with its partners establish its control over that facility, (b) it is practically impossible to duplicate the scanning that Google did (or rather, that it is a complete waste of public funds to duplicate this effort when the images exist and were created from content purchased through public funds), (c) the clauses deny full use rights to the Participating Libraries as well as limit the sharing of these images to others including potential competitors, and (d) Google does not need to invest addition time, effort, or money to lift the restrictions.

\footnotetext{
${ }^{34}$ MCI Communications Corp. v. American Tel. and Tel. Co., 708 F.2d 1081, 1132 (7th Cir. 1983).

${ }^{35} \S 2: 7$. The essential facilities doctrine, in INTERNATIONAL TRADE AND U.S. ANTITRUST LAW $\S 2: 7$ (2d ed.)
} 
Even in its standard formulation, the use of this doctrine is controversial, rare, and also usually goes through the courts. The reason that private legislation is suggested in this instance instead is because the intent is not to open up the use of Google's database to all comers but rather just to end its right to stop its Library Partners from using digital copies of resources it already owns. The doctrine is raised only to establish a possible parallel for a basis for the right of the federal government, in the form of Congress, to intervene.

Third, falling under citizens' privacy writ large --- which is not the right to privacy within the Constitution, which only protects against state intrusions on privacy --- the contract provisions have the purpose of protecting a monopoly in a manner that violates the privacy of the nation's citizens. It is already well known that Google collects information on the users of all of its tools, a cost to the public to which users are generally not asked to consent. By prohibiting libraries from utilizing the images, Google is using its monopolistic control over the digital images to gather personal information on users, both (1) creating yet another data store with commercial implications and (2) preventing libraries from creating privacy-protecting alternatives to Google's databases.

\section{Other Objections to Private Laws}

In the past, private laws have come under the greatest criticism for being inequitable, granting a specific benefit or relief only to a single person or a small group of people. Everyone else similarly situated will not get the benefit of the legislation. ${ }^{36}$ However, in the case of information, it is possible that a private law could actually increase equity, not in how the party or similar parties are treated, but simply by enabling wider, fairer access to information.

The other common objection to private laws, and what led to a significant decline in use, was evidence of corruption in the legislative process. ${ }^{37}$ In the 1960 s and 70 s, there were numerous allegations of bias or inappropriate behavior. Lawmakers or their aides were accused of taking bribes or soliciting bribes to introduce private legislation. It would be difficult to see how the legislation being proposed in this paper would be subject to bias, as it is obviously for the public benefit, via libraries, not for any individual, corporate, or for-profit interest. The Partner Libraries obviously would benefit over all others, but since their missions are to serve broad communities, the benefit would not be fully contained even if they chose to take no further action.

\section{Post-Enactment Actions By Library Partners}

To see the full impact of this type of private legislation, two actions by the libraries owning the images would be necessary. First, because private laws are rarely undertaken without a request

\footnotetext{
${ }^{36}$ Supra note 31 at 1704.

${ }^{37}$ Mantel, supra note 25 at 92.
} 
from one of the parties involved,$^{38}$ the libraries would have to be willing to bring the matter to Congress' attention $^{39}$. The second necessary step would come after any private law was enacted, as the effect of the law would not be felt by the public unless the libraries owning these images share them with others beyond what they have been doing through HathiTrust.

In the following sections, while possibilities with this second step are explored, the original Google-Partner-Library will be referred to as the OL (Owning Library), and any library receiving the copies of the images will be referenced as RL (Receiving Library).

\section{Expanded Access}

If private legislation is passed, the simplest and most obvious step for an OL library to take is to expand public access to its works. This could be as basic as duplicating some of the services that Google offers, allowing the public to search the full texts of its databases and presenting search results in the form of snippets or limited full pages instead of just hit counts. Or, an OL library could take more expansive steps, allowing Wikipedia or other reference sources (e.g., newspapers) to link to the works, much as the Internet Archive does, even if it does not allow any more than viewing the page referenced. Such linking could even be made available to the public, through direct linking, a link creation tool like those provided by databases ${ }^{40}$ or authentication portals (e.g., OpenAthens) ${ }^{41}$ or by establishing consistent and publicized URL schemas such that on-the-fly, dynamic linking is possible. But none of these actions in isolation have the impact of an aggregated national collection, a step that might be possible through other means.

\section{Controlled Digital Lending}

$\mathrm{CDL}$ is a library effort to ensure that legitimately acquired library materials remain useable despite changes in technology, which come much more rapidly now than ever before, or user preferences in formats. Presently, the initiatives focus on digitizing material and lending these eversions in place of the original physical items, but the same general principles could apply to

\footnotetext{
${ }^{38}$ Technically, there is an alternative mechanism for referral, though the Comptroller General, this does not appear to be regularly used. Supra note 31 at 1688, referencing 45 Stat. 413 (1928), 31 U.S.C. § 236 (1964).

${ }^{39}$ An argument could be made that since the harm is to the public, a member of the public could put the request to Congress. But since the subsequent actions would require a Participating Library's involvement anyway, the only assured path to full advancement of the ideas in this article mean that a Participating Library would be willing to be a driver for change.

${ }^{40} \mathrm{https}$ ://lawschool.westlaw.com/admin/wllinkcreator/wllinkcreator.aspx (last visited July 15, 2021).

${ }^{41} \mathrm{https} / / /$ docs.openathens.net/display/public/MD/Redirector+link+generator (last visited July 15, 2021).
} 
other technologies. The detailed fair use analysis of CDL is well documented elsewhere ${ }^{42}$ so will not be rehashed here.

While CDL implementations may vary in specifics, all share common characteristics:

Properly implemented, CDL enables a library to circulate a digitized title in place of a physical one in a controlled manner. Under this approach, a library may only loan simultaneously the number of copies that it has legitimately acquired, usually through purchase or donation. For example, if a library owns three copies of a title and digitizes one copy, it may use CDL to circulate one digital copy and two print, or three digital copies, or two digital copies and one print; in all cases, it could only circulate the same number of copies that it owned before digitization. Essentially, CDL must maintain an "owned to loaned" ratio. Circulation in any format is controlled so that only one user can use any given copy at a time, for a limited time. Further, CDL systems generally employ appropriate technical measures to prevent users from retaining a permanent copy or distributing additional copies. ${ }^{43}$

Each of CDL's three requirements deserve further elaboration. The first requirement is that any library engaging in CDL must have legitimately acquired the physical works to be digitized, typically through gift or purchase. This means that the copyright owner received remuneration for her work at the time the physical work was first purchased, and that the entity copying and lending the work is an owner of a legitimately acquired copy.

Second, a CDL provider conforms to an own-to-loan ratio, lending out only the number of copies legitimately acquired. The number of copies a library can circulate remains the same both pre- and post-format shifting. Therefore, under CDL, a library cannot digitize a work to increase the number of copies used over the number owned.

Last, all adopt digital rights management (DRM) tools to control use, so that a digital version of a book cannot be copied wholesale, redistributed by the user, or accessed by more users than permitted by the number of copies the library owns. Some of the tools used in current initiatives are the same ones used by the publishing industry for their e-books - Overdrive and Adobe Digital Editions - so the protections are the same as established standards. Since the

\footnotetext{
${ }^{42}$ Position Statement on Controlled Digital Lending, CONTROLLED Digital LENDING By LiBRARIES, https://controlleddigitallending.org/statement; Dave R. Hansen \& Kyle K. Courtney, A White Paper on Controlled Digital Lending of Library Books, CONTROLLED DigITAL LENDING BY LIBRARIES (2018), https://controlled digitallending.org/whitepaper; Michelle M. Wu, Revisiting Controlled Digital Lending Post ReDigi, 24 FIRST MONDAY (2019), https://firstmonday.org/ojs/index.php/fm/article/ view/9644/7793; Michelle M. Wu, Piece-by-Piece Review of Digitize-and-Lend Through the Lens of Copyright and Fair Use, 36 LEGAL REF. SERVS. Q. 51 (2017).

${ }^{43}$ Lila Bailey, et al., Position Statement on Controlled Digital Lending at https://controlleddigitallending.org/statement (last visited January 31, 2019)
} 
pandemic, libraries have begun exploring other platforms, but all so far contain similar DRM restrictions.

It is important to note that CDL is not a proposal for anyone to be able to format shift and lend; it is only intended for libraries, and this element has been a core aspect of the framework. This narrow configuration makes sense in context, as libraries have a unique standing in society and in copyright law ${ }^{44}$. The vast majority of libraries are non-profit, non-commercial entities charged with serving the public interest, though corporate libraries may be an exception. This article looks at the majority only, with public and academic libraries as the models.

Private legislation could facilitate the public reach of CDL in three ways. The first would take shape if one or more of the OLs elects to share its collection with the general public, still complying with the principles of CDL but allowing anyone, including those in smaller and poorer communities, to access works their libraries do not hold and they would otherwise be unable to read. To understand the scope of the potential impact, approximately $77 \%$ of all public libraries in the nation are small or rural libraries, ${ }^{45}$ and in 2019 , over $50 \%$ of all public libraries had an annual collection budget of under $\$ 34,000^{46}$. When considering budget, the cost of books, and inflation rates, these libraries simply have fewer means to obtain content than better funded libraries. Better funded libraries in larger communities may be reluctant to share all works, particularly those in high demand, but CDL platforms can be deployed to share broadly only portions of a collection, allowing broader use of lesser-used materials while preserving highdemand materials only for local use.

The second path for expansion goes to the unwritten requirement of any CDL program --that there be a digital equivalent available to be used in place of the owned physical title. In many cases, this is accomplished through some sort of format shifting. A library would convert the content in the physical article acquired into a different format, in this case, an electronic format through digitization, with the intention of using the new format in place of the old. In instances where a library may own more than one copy, it may choose to use the new format in place of only a percentage of the owned copies, using some in their original formats and others in their converted ones. Though the digitized works are likely to be processed for optical character recognition, for searching and screen reader functionality, the content of the work remains the same as the original. The library makes no edits or changes to the work itself.

If the Google contract terms limiting sharing are nullified, and if OLs are willing to share their images broadly with other libraries already owning physical copies of the same works, they would reduce the workload on the nation's libraries, as none of those libraries would need to

\footnotetext{
4417 U.S.C. $\$ 108$.

${ }^{45}$ Deanne W. Swan, Justin Grimes, \& Timothy Owens, The State of Small and Rural Libraries in the United States, Institute of Museum and Library Services (Sept. 2013), https://www.imls.gov/sites/default/files/publications/documents/brief201305.pdf.

${ }^{4646}$ Public Libraries Survey, Table 11A. Total collection expenditures of public libraries in the 50 states and the District of Columbia and percentage distribution of expenditures, by type of expenditure and population of legal service area: Fiscal year 2019, Institute of Museum and Library Services, https://www.imls.gov/sites/default/files/2021-05/fy2019_pls_tables_7_thru_13a.xlsx.
} 
digitize these titles themselves. They would simultaneously free up these libraries' time to digitize titles not yet converted to digital form, which they, in turn, could then share with other libraries. In this manner, the nation's libraries' physical collections can all be methodically digitized, maximizing the efforts of every library to advantage society at large. In terms of immediate effect, this sharing would also expand exponentially the number of digital copies available for circulation at any given time, across different communities. A single instance of digitization could provide the e-book equivalents to thousands of libraries that already own a print copy. It would similarly allow more libraries to make their works available for lending to other communities (via ILL or otherwise), or linking to sources like Wikipedia or newspapers so that verification is streamlined.

The last and most publicly beneficial outcome of private legislation would be a merger of the concepts in the first and second paths. If every library obtaining copies of images from an OL were willing to share their resulting e-copies with the public through CDL and though a unified interface, ${ }^{47}$ a significant portion of the information divide caused by poverty would be addressed. In many cases, multiple copies of the same title would be available to the public for checkout, regardless of location or wealth, easily found and accessed. For Wikipedia, news sites, and social media users, there would be no need to scour multiple sites or libraries for a source for verification; a single entry point would provide pointers to all sources available for those interested in supporting their statements with fact.

\section{Fair Use Analysis for the Sharing of Library Images}

Past scholarship has already made the argument that the sharing of digitized images with other libraries for CDL purposes falls under fair use. ${ }^{48}$ As a reminder, fair use is currently codified in $\S 107$ :

Notwithstanding the provisions of sections 106 and 106A, the fair use of a copyrighted work, including such use by reproduction in copies or phonorecords or by any other means specified by that section, for purposes such as criticism, comment, news reporting, teaching (including multiple copies for classroom use), scholarship, or research, is not an infringement of copyright. In determining whether the use made of a work in any particular case is a fair use the factors to be considered shall include-

\footnotetext{
${ }^{47}$ One vision of a collective, national database is detailed in Michelle M. Wu, Shared Collection Development, Digitization, and Owned Digital Collections, 44 Coll. MANAGEMENT 131 (2019).

${ }^{48}$ Michelle M. Wu, Piece-by-Piece Review of Digitize-and-Lend Through the Lens of Copyright and Fair Use, 36 LEGAL REF. SERVS. Q. 51, 67-68 (2017).
} 
(1) the purpose and character of the use, including whether such use is of a commercial nature or is for nonprofit educational purposes;

(2) the nature of the copyrighted work;

(3) the amount and substantiality of the portion used in relation to the copyrighted work as a whole; and

(4) the effect of the use upon the potential market for or value of the copyrighted work.

The fact that a work is unpublished shall not itself bar a finding of fair use if such finding is made upon consideration of all the above factors.

This test is the one most often applied when a copyright owner's exclusive rights are exercised without authorization or remuneration and a public interest is invoked. The primary principle behind fair use is the belief that the public benefit in some uses can justify the abridgement of author's rights to control their work or to obtain payment for the use of their work. ${ }^{49}$ The four factors listed must be addressed by any court faced with a fair use claim, but jurists are not limited to examining only these issues when they conduct their analysis. In practice, scholars have shown that the second and third factors of the legal analysis have been subsumed by the first and fourth factors, ${ }^{50}$ so the only two factors that will be discussed in the following three subsections are the two that remain relevant.

Despite the fair use claims for the sharing of digitized books, the reality is that CDL has not yet been tested by the courts, and general counsel offices are directed to focus on risk. Even officers that believe CDL is legal might view this type of sharing as unnecessarily increasing risk beyond basic CDL, especially as they cannot guarantee that a receiving library would use the images only for CDL. Therefore, this section looks at additional steps that an OL might take to ease the minds of their legal advisors.

\section{Receiving Library's Written Assumption of Responsibility}

The OL could (1) limit any sharing to other non-profit libraries only and (2) require the recipient to certify that they own a copy of the work(s) for which they're requesting digital images and that the digital copies will be used only for CDL. Ownership of these copies would permanently

\footnotetext{
${ }^{49}$ See, Lyman Ray Patterson, Understanding the Copyright Clause, 47 J. COPYRIGHT SoC'Y U.S.A. 365 (2000).

${ }^{50}$ See, Barton Beebe, An Empirical Study of U.S. Copyright Fair Use Opinions, 1978-2005, 156 U. PA. L. REV. 549 , 584 (2008); Neil Weinstock Netanel, Making Sense of Fair Use, 15 LEWIS \& CLARK L. REV. 715, 736 (2011).
} 
transferred to the RL. This should clearly limit any OL liability to the sharing of the image itself and not to any subsequent actions by the recipient library, and any sharing would fall squarely within fair use in an analysis similar to that applied to CDL. The analysis in brief:

The purpose and character of use, the first factor, most often weighs against fair use in two instances: where the use is commercial, ${ }^{51}$ or where it is used "to supersede the use of the original work" ${ }^{, 52}$ without compensating the copyright owner. The second of these appears to be less important, as there have been many uses that have been determined to be fair even where the use supersedes the use of the original. In all cases, the uses have been non-commercial.

Examples include the Betamax and its recording of shows that made it unnecessary to watch the original, ${ }^{53}$ the use of Google's thumbnail images instead of the full-sized originals, ${ }^{54}$ and the provision of digitized full-text copies of books to the print disabled. ${ }^{55}$

In the sharing scenario described in this subsection, the use would be non-commercial, as the OL would be providing the images to the RL without any compensation or benefit and for the purpose of replacing the RL's physical copy with this digital copy in compliance with the principles of CDL. As with CDL generally, the digital copies would be used in place of physical copies and therefore serve the same purpose as the physical copy did - to get acquired content to users. The use does substitute for using the original, but unlike most fair use cases, the original in this instance is a copy that the library already purchased and owned. Because the use falls within a core library purpose (lending), simply changes the form of the object and not the purpose or content of use, and no more copies are used than owned, this factor should favor fair use.

Looking now to the fourth factor, the impact on the market or potential market for the work, no harm should be found. The work is being shared for the stated purpose of CDL, where both libraries have already paid the copyright owner(s) for the works and no more copies are used than purchased. The digital copy being shared merely takes the place of the RL's physical copy and therefore does not displace any unsold copy on the market. The number of copies in use, even across all libraries sharing these images, will not be increased. As the number of copies in use are no more than the number of copies authorized by the author (even if they are being used in different formats), there is no market harm. The number of copies that would have been sold to libraries have been sold to libraries; all libraries have done is to determine that a different form, not a changed number of copies, is needed. As with the first factor, the fourth factor should also favor fair use.

\section{Notice of Copyright and Limitation of Liability}

\footnotetext{
${ }^{51}$ Sony Corp. of Am. v. Universal City Studios, Inc., 464 U.S. 417, 449 (1984) (noting that under the first factor, commercial use is presumptively unfair, and non-commercial, non-profit uses are presumptively fair).

${ }^{52}$ Folsom v. Marsh, 9 F. Cas. 342, 345 (C.C.D. Mass. 1841)

${ }^{53}$ Sony, supra note 51.

${ }^{54}$ Perfect 10, Inc. v. Amazon.com, Inc., 508 F.3d 1146 (9th Cir. 2007).

${ }^{55}$ Authors Guild, Inc. v. HathiTrust, 755 F.3d 87 (2d Cir. 2014)
} 
Alternatively, to avoid the type of recordkeeping necessary with written agreements, the OL could take an approach guided by long-standing ILL practices, simply embedding a copyright notice on the scans. That notice would state that the images are being provided to a non-profit library for use by that library for legitimate library uses. Ownership of the copies again transfers to the RL upon receipt, and the RL is responsible for any subsequent uses. ILL practices, of course, are notably different, justified by $\$ 108$ and intended for the private use of an end-user. If the OL is sharing the images with another library outside of the purposes of $\S 108$, then that action would need to be justified under one of the other exceptions, fair use.

While the analysis is not as straightforward as in the first option above, sharing under this scenario should also be seen as fair. The purpose and character of use would again be noncommercial, as the OL would be providing it to the RL without any compensation or benefit and for the purpose of enabling the RL's library legitimate uses of the images. That the OL does not dictate what is legitimate should not injure its standing under this factor unless (1) the RL was intending to use the images illegally and (2) the OL library was aware of this intent before sharing. The OL has made and distributed a copy to another library, but fair use caselaw provides a long list of instances where reproduction and distribution by themselves have been deemed fair. ${ }^{56}$ The circumstances here, where the OL knows that the RL already has a physical copy in its collection and where the OL has no knowledge of an intent to infringe copyright, would seem to support a fair use claim as well.

The more problematic analysis here falls to the fourth factor, as there is no longer any promise or statement by the RL library that it will be using the images only for a specific function - CDL - or even that the RL library owns a physical copy of the work. However, if the OL only provides these digitized images to libraries that own a physical copy, it again could argue that the provision of the copy by itself has no market effect. By sharing, the OL library did not increase the number of the copies on the market. It provided a digital copy to another library that already had purchased a copy, but that copy has no practical effect on any market unless it is used. Because the embedded copyright notice clearly states that the RL library assumes responsibility for subsequent uses, if the RL library then uses the work inappropriately, its actions may fall under infringement, but the OL would have had no role in the decisions regarding use of the images. In this configuration of sharing, the fourth factor should also lean towards fair use.

The analysis may change if the RL library does not own a copy of the work independent of the digital copy. While sharing may still be permitted under $\S 108$ for ILL or preservation purposes, those reasons and uses are narrow. The conditions under which an OL might share a work with an RL outside of $\S 108$ are so varied that it is impossible to apply a fair use analysis to all without specific contexts.

Overall, even though the argument for fair use in this subsection may fall into a greyer area than the first subsection, there are societal reasons why both the OL and RL might prefer

\footnotetext{
${ }^{56}$ Perfect 10, supra note 54 (thumbnail images on Google Images); HathiTrust, supra note 55 (digitized books to the print disabled); Cambridge Univ. Pr. v. Patton, 769 F.3d 1232 (2014) (e-course reserves).
} 
this version. It not only (1) eliminates the need to duplicate effort in digitizing, OCR-ing, and adding metadata and (2) shifts liability, but it also allows the RL library to undertake more innovative uses with the work, if it is more open to risk than the OL. For example, the RL might revive a speech-to-text practice attempted by Amazon in 2009 with its Kindle $2,{ }^{57}$ including for downloaded books. Or, it could enable selected copying and pasting (e.g., up to a paragraph), to make it easier for users to create citations, much like the limited copying and pasting available in some databases like Lexis and Westlaw, which allow the user to copy not only a specific amount of text, but also the citation of the work. Each of these actions comes under a separate fair use analysis so could be viewed as adding risk, but both also serve legitimate research and public interest functions (e.g., assisting those with disabilities) that an RL may want to further.

\section{Self-Service Repository}

A third option would be the most ambitious and expensive but would carry secondary benefits even greater than those explored in the first two subsections. That option would be depositing all of the images into a central repository for all non-profit libraries to use. The repository preferably would be managed by a government organization with the same preservation and access interests as libraries (e.g., Library of Congress or the National Archives), as this would place the cost of maintaining a public good with the government and would ensure the preservation of the images regardless of the existence of any other institution, but it could be established independently as well.

As with the second option, there are too many permutations on how such a repository could be structured, so a full fair use analysis is impossible without specifics. However, one configuration will be outlined for the purposes of illustration.

Imagine a repository where every OL deposits its images, and where any non-profit library could obtain an authenticated account (or another restricted, verified path such as a static IP) to download images. To establish an account, a library would first have to certify that it is a non-profit library; accept all responsibility for activity on the account and subsequent use of images; guarantee that it will take appropriate security measures with the account (e.g., password management in accordance with best practices); pledge that it will not download any images of works where it does not already own a copy of the work; acknowledge that the images of works not in the public domain are protected by copyright and that the library bears responsibility for complying with copyright in their use. The account user, then, would be able to search and download images without mediation. The repository could take extra precautions by requiring each library downloading a work's digital copies to enter its library system's record of the owned copy (e.g., order or item record number) before each download.

\footnotetext{
${ }^{57}$ Mike Masnick, Amazon Gives In to Ridiculous Authors Guild Claim: Allows Authors to Block Text-To-Speech, TECHDIRT (Feb. 27, 2009), https://www.techdirt.com/ articles/20090227/1759173928.shtml. Note that the Internet Archive already provides a text-to-speech feature in online reading of the materials in its Open Library.
} 
Sharing under this scenario should also be seen as fair. The purpose and character of use would again be non-commercial, as the OL would be providing it to the repository without any compensation or financial benefit and for the purpose of (1) preserving the images, and (2) enabling other libraries' legitimate uses of the images. Because the conditions under which libraries can use the images are limited by their agreement with the repository, the OL has no reason to believe that the images will be used for anything other than legitimate purposes. The OL has made and deposited a copy to the repository, but as noted in the subsection above, caselaw has established that the storage of copies, even multiple copies, can be fair. The first factor, then, should favor fair use.

Under the fourth factor, the provision of the copy should have no market effect. By sharing, the OL library did not increase the number of the copies on the market. It provided a digital copy to a repository for preservation and use by other libraries with owned copies. As in the other two subsections, the copy uploaded to the repository has no practical effect on any market unless it is used. As the conditions for library use (1) limit the use of downloads only to images where the library owns a copy of the work and (2) clearly place responsibility for copyright compliance the RL, the OL library's deposit with the repository should not be confused with subsequent use. In this configuration of sharing, then, the fourth factor should also lean towards fair use.

Of course, a complication is triggered if the OL is also the repository, in which case, the most relevant cases may seem to be the litigation surrounding early file sharing platforms (e.g., Napster, Grokster) ${ }^{58}$ where each of the uses were found to be unfair. In those cases, file sharing platforms allowed users to anonymously upload or download music where the music may never have been owned by either the uploaded or downloaded. Some openly advertised their platforms as mechanisms to get free music and failed to take action even though they were well aware of infringing uses. ${ }^{59}$ All of those cases can be distinguished easily from libraries sharing images of copyrighted works with other libraries that already own copies of those works.

On the first factor, each of the file sharing platforms engaged in commercial activity, whether charging for advertising ${ }^{60}$ or through "repeated and exploitative unauthorized copies of copyrighted works were made to save the expense of purchasing authorized copies." 61 Though the platforms did advance some arguably legitimate purposes, such as owners of CDs using the platforms to download the digital versions of those CDs in space-shifting, the court rejected the claim because the platforms did not provide these versions only to owners but also to the general public. ${ }^{62}$ In this subsection's proposal, a repository would not be engaging in commercial activity, its use is not to save the expense of purchasing authorized copies (as all libraries using

\footnotetext{
${ }^{58}$ A\&M Recs., Inc. v. Napster, Inc., 239 F.3d 1004 (9th Cir. 2001), as amended (Apr. 3, 2001), aff'd sub nom. A\&M Recs., Inc. v. Napster, Inc., 284 F.3d 1091 (9th Cir. 2002), and aff'd sub nom. A\&M Recs., Inc. v. Napster, Inc., 284 F.3d 1091 (9th Cir. 2002); Metro-Goldwyn-Mayer Studios Inc. v. Grokster, Ltd., 545 U.S. 913, 125 S. Ct. 2764, 162 L. Ed. 2d 781 (2005).

${ }^{59}$ Grokster, supra note 58 at 923-27.

${ }^{60} I d$. at 926.

${ }^{61}$ Napster, supra note 58 at 1015.

${ }^{62} I d$. at 1019.
} 
the works would have had to have legitimately obtained copies), and the repository would not make the images available to the public but would only provide access to verified libraries for specific uses.

On the fourth factor, in the case of file sharing, the litigants presented dueling reports on whether or not the platforms harmed or benefitted the works and while the courts struggled with determining the veracity of any report, what doomed the platforms was largely the fact that the commerciality of their activities allowed the courts to presume harm. ${ }^{63}$ As a repository's actions relating to the sharing of library digital images would be non-commercial, that presumption is not only lifted but works in the other direction. Based on Sony, the presumption should be that there is no harm, and copyright owners would need to provide evidence of harm or the likelihood of harm. Because of the design of the agreement between the repository and downloading libraries, that harm would be difficult to prove. Each library would have already purchased a copy of the work; so long as they use that work in line with CDL principles, the number of copies used nationwide would be no different pre- or post-download. The same number of copies used would be the same number purchased.

For many reasons, this option would provide the greatest overall benefit for society. Not only does it capture the flexibility in innovation as noted in the second option, but it (1) provides a searchable repository that can also be used as a read-only centralized catalog of all works digitized so that libraries would know what has already been digitized before undertaking the time and expense to digitize a new title; (2) encourages purchasing books insofar as libraries that want to use the digital images must own a copy, and those that do not already own the works may therefore be prompted to search out physical copies; (3) establishes a central clearinghouse where images can be uploaded as well as downloaded, enabling all libraries to collaborate on digitizing the world's published works more effectively.

\section{Conclusion}

Unfiltered, unverified information flows freely on the web and is much more easily found and used than reliable sources. There are logical reasons for this, as quality, reliable information often costs both time and money to investigate, verify, and publish. However, that type of investment only justifies the charging for the information at the outset, not the cabining of it once it is available and has been purchased. Where public libraries have acquired content, they should be allowed to maximize its use in society within the bounds of copyright. Such use is within the spirit of copyright and its hope for an informed citizenry and more equal access to information. Private legislation coupled with library collaboration on multiplying access points could make quality information available to the public in a quantity and manner that could help fight the war on misinformation.

${ }^{63} I d$. at 1017, citing Sony ("If the intended use is for commercial gain, that likelihood [of market harm] may be presumed. But if it is for a noncommercial purpose, the likelihood must be demonstrated."Sony, 464 U.S. at 451). 